\title{
Ferrule: A Literature Review
}

\author{
Ashok J Abraham ${ }^{1}$, Chinnu R Koshy², Shankar Narayanan ${ }^{3}$, Veni Ashok ${ }^{4}$, Rajasekaran M Sundaran ${ }^{5}$,
} Sokkalingam M Venkatesan ${ }^{6}$

\begin{abstract}
Statement of problem: Endodontically treated teeth are known to have reduced structural strength. Glass fiber posts may influence fracture resistance and should be evaluated.

Purpose: The purpose of this study was to evaluate the influence of glass fiber post length on the fracture resistance of endodontically treated teeth.

Materials and methods: Forty intact human maxillary canines were selected and divided into four groups, the control group consisting of teeth restored with a custom gold cast post and core, with a length of two thirds of the root. Other groups received prefabricated glass fiber posts in different lengths: group I/III, removal of one third of the sealing material $(5 \mathrm{~mm})$; group I/II, removal of one half of the sealing material (7.5 $\mathrm{mm}$ ); and group II/III, removal of two thirds of the sealing material $(10 \mathrm{~mm})$. All the posts were cemented with resin cement, and the specimens with glass fiber posts received a composite resin core. All the specimens were restored with a metal crown and submitted to a compressive load until failure occurred. The results were evaluated by one-way analysis of variance (ANOVA) and the all pairwise multiple comparison procedures (Tukey honestly significantly difference test; $\alpha=0.05$ ).

Results: The ANOVA showed significant differences among the groups $(p<0.002)$. The Tukey test showed that the control group presented significantly higher resistance to static load than the other groups (control group, 634.94 N; group I/III, $200.01 \mathrm{~N} ;$ group I/II, $212.17 \mathrm{~N}$; and group II/III, $236.08 \mathrm{~N}$ ). Although teeth restored with a cast post and core supported a higher compressive load, all of them fractured in a catastrophic manner. For teeth restored with glass fiber posts, the failure occurred at the junction between the composite resin core and the root.

Conclusion: The length of glass fiber posts did not influence fracture load, but cast post and cores that extended two thirds of the root length had significantly greater fracture resistance than glass fiber posts.

Keywords: Crown margin, Dowel, Ferrule, Post and core, Shoulder.

Journal of Operative Dentistry and Endodontics (2019): 10.5005/jp-journals-10047-0078
\end{abstract}

\section{INTRODUCTION}

Postendodontic restoration plays an important role in the clinical success of an endodontically treated tooth. It has been a great challenge for clinicians when considering the restoration of endodontically treated teeth even though a variety of treatment options are available. ${ }^{1}$ The amount of tooth dentin remaining above the level of gingiva determines the method of postendodontic restoration, and a post and core is indicated when sufficient tooth structure is not present to retain an artificial crown. The most commonly used and standardized post system for many years was cast post and core systems. Later fiber reinforced composite (FRC) posts were introduced to make the post and core systems less technique sensitive and esthetically advanced. ${ }^{2}$ Preserving the pericervical dentin to create a ferrule is important for better biomechanical behavior of restored tooth. ${ }^{3}$ The term "ferrule" was originated from the Latin words "ferrum" meaning iron and "viriola" which is bracelet. Thus, ferrule is the band of metal encircling the coronal surface of the tooth. ${ }^{4,5}$

\section{Materials and Methods}

A literature search was conducted based on the following criteria: articles retrieved in PubMed using the following keywords: "ferrule" and "ferrule effect" alone or in combination with "literature review," "fracture resistance," English language, and publication date ranging from 1995 to 2017. This search strategy identified 40 articles. Articles that were not found to be significant to the subject of the review based on the abstract were not included. Forty articles were

\footnotetext{
${ }^{1-6}$ Department of Conservative Dentistry and Endodontics, Ragas Dental College, Chennai, Tamil Nadu, India

Corresponding Author: Chinnu R Koshy, Department of Conservative Dentistry and Endodontics, Ragas Dental College, Chennai, Tamil Nadu, India, Phone: +91 9789044299, e-mail: chinnu.n08@gmail.com

How to cite this article: Abraham AJ, Koshy CR, Narayanan $S$, et al. Ferrule: A Literature Review. J Oper Dent Endod 2019;4(2):92-95.

Source of support: Nil

Conflict of interest: None
}

found to meet the mentioned inclusion criteria and became the object of the present review.

\section{Discussion}

\section{Ferrule Effect}

A ferrule effect is defined as a "metal collar of the crown surrounding the walls of the dentin extending coronal to the margin of the preparation. The result is an elevation in resistance form of the crown from the extension of dentinal tooth structure." ${ }^{\prime 6}$ The ferrule defined by "The Glossary of Prosthodontic Terms" is a metal band or ring used to fit the root or crown of a tooth. It is an extension of the restored crown which, by its hugging action, prevents shattering of the root. ${ }^{6}$ According to the literatures, $1.5-2 \mathrm{~mm}$ tooth ferrule height is needed to provide retention and resistance to the post and core (Fig. 1). ${ }^{6,7}$

() The Author(s). 2019 Open Access This article is distributed under the terms of the Creative Commons Attribution 4.0 International License (https://creativecommons. org/licenses/by-nc/4.0/), which permits unrestricted use, distribution, and non-commercial reproduction in any medium, provided you give appropriate credit to the original author(s) and the source, provide a link to the Creative Commons license, and indicate if changes were made. The Creative Commons Public Domain Dedication waiver (http://creativecommons.org/publicdomain/zero/1.0/) applies to the data made available in this article, unless otherwise stated. 


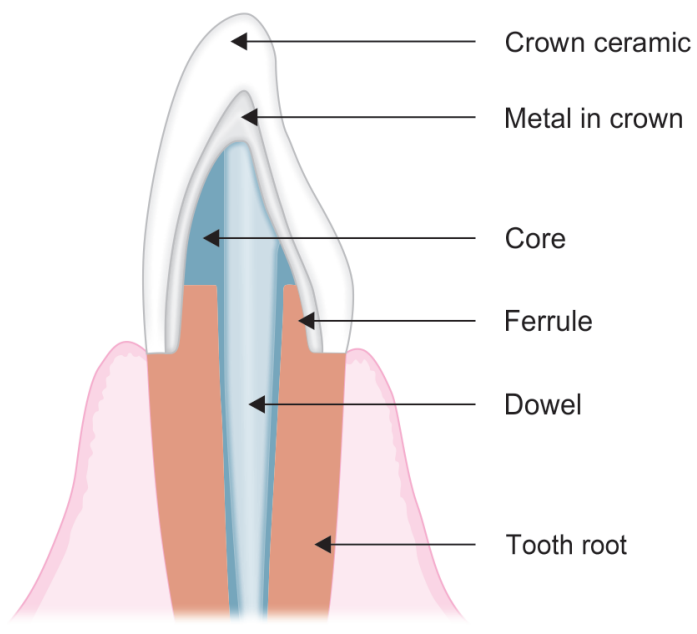

Fig. 1: Tooth-post and core system

\section{Ferrule Tooth Structure}

The "ferrule tooth structure" is the amount of tooth structure extending 1.5-2.0 mm coronal to the margin of the prepared tooth and will be encircled by the apical $1.5-2.0 \mathrm{~mm}$ of the intaglio or tissue surface of the crown or ferrule margin. The ferrule tooth structure increases the fracture resistance of tooth along with post and core after a crown is luted on it. It also reduces the force that is exerted on the root surface by a post after crown placement. The tooth structure, post and core material, that extends to coronal from the tooth margin, present within the volume encircled by the apical 1.5-2.0 mm of the ferrule margin is referred as "ferrule tooth complex" (Fig. 2). ${ }^{8}$

Some tooth structure helps to prevent posterior tooth without ferrule from splitting into two separate buccal and lingual halves, along a fracture line that goes from the mesial to the distal. Examples of this are the oblique ridge of maxillary molar and the tooth structure located coronal to the roof of a pulp chamber of a posterior tooth. If such buccal-to-lingual binding tooth structure is connected, in a continuous line that is parallel with the imaginary axes of a cylinder preparation of that abutment, to tooth structure that is located at the ferrule margin, the apical $1.5-2.0 \mathrm{~mm}$ of this tooth structure adds to the ferrule tooth structure.

\section{Role of Ferrule Effect}

When a tooth with no crown structure above the cementoenamel junction (CEJ) is prosthetically rehabilitated with post and core, the post transfers the complete occlusal forces intraradicularly which can lead to vertical root fracture. When the artificial crown extends apically from the core margin encircling the sound tooth structure, it serves as a reinforcing ring or "ferrule" to help protect the root from vertical fracture. A number of studies have reported to improve fracture resistance for pulpless teeth restored with a ferrule. A recent in vitro study by Isidor et al. evaluated the effects of post length and ferrule length on resistance to dynamic loading of bovine teeth in vitro and concluded that the mean resistance to failure was greatest for the group restored with a combination of the longest posts $(10 \mathrm{~mm})$ and the longest ferrules $(2.5 \mathrm{~mm})^{9}{ }^{9}$

A ferrule also helps protect the integrity of the cement seal of the artificial crown. This was supported in an in vitro study

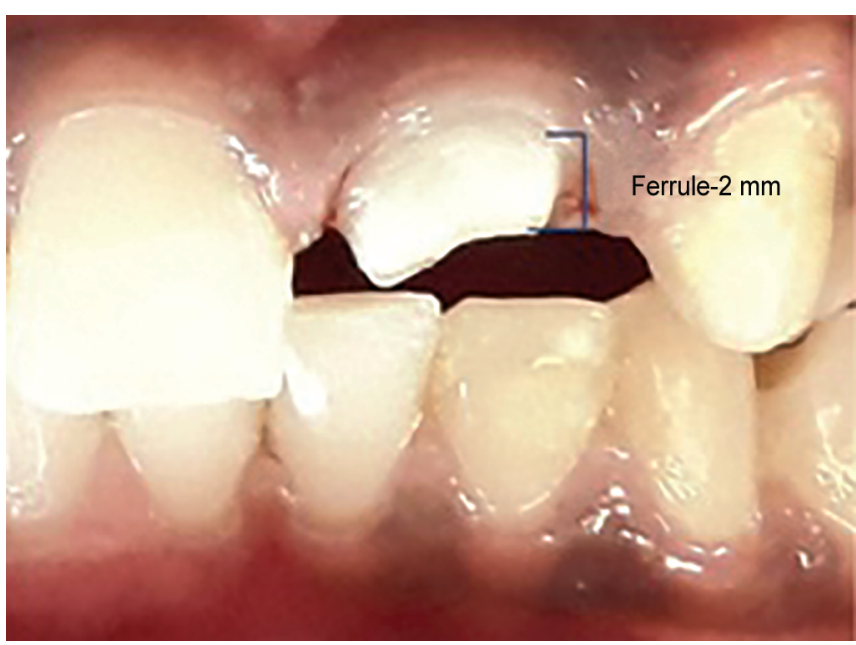

Fig. 2: Ferrule tooth structure

conducted by Libman and Nicholls where they concluded that there was improved resistance to fatigue failure of the crown cement seal when the crown margin extended at least $1.5 \mathrm{~mm}$ apical to the margin of the core. ${ }^{10}$ Another study by evaluated the clinical success and failure characteristics of teeth restored with posts and artificial crowns and reported a higher potential for the fracture of posts when the cemented crowns did not provide a ferrule effect. $^{2}$

When preparing a tooth for a cast post and core, a contrabevel is advocated to produce a cast core with a collar of metal that encircles the tooth and serves as a secondary ferrule independent of the ferrule provided by the cast crown. Nevertheless, there seems to be little advantage to this secondary ferrule as a component of the core. A study by Loney et al. reported significantly higher mean stresses with collared cores, suggesting that incorporating a ferrule as an integral part of a cast core was undesirable. ${ }^{11}$

\section{Ferrule Design}

\section{Ferrule Height}

The adequate ferrule height needed for proper resistance and retention has been evaluated in many studies. A study using crowned bovine teeth was conducted by Assif et al., where the bovine teeth were subjected to cycling loading until the crown or post was dislodged or the post or root fractured. It was observed that the resistance increased significantly with an increasing ferrule height. Similarly, the number of load cycles required to induce failure in the cement layer was higher for teeth with higher ferrule. Based on the studies, $1 \mathrm{~mm}$ of coronal dentin was also found to be enough to significantly increase the fracture strength when exposed to static loading. ${ }^{7}$

While two other studies reported no statistically significant difference in failure loads between teeth with a $1 \mathrm{~mm}$ ferrule and those with no remaining coronal tooth structure. ${ }^{12}$ In another study conducted, teeth with a $0.5 \mathrm{~mm}$ and $1 \mathrm{~mm}$ ferrule failed significantly even in lower number of load cycles than the $1.5 \mathrm{~mm}$ and $2 \mathrm{~mm}$ ferrule groups. ${ }^{10}$

Based on the various studies and literature review, it was highlighted that ferrule heights required to significantly improve fracture resistance and retention when exposed to static and dynamic loading were $1.5-2 \mathrm{~mm}$. 


\section{Ferrule Width}

The significance of the remaining axial wall thickness of dentin and its role in preventing tooth fracture also have been investigated in some literatures. Some studies have implicated the amount of residual axial tooth structure to be significant in resisting fracture, whereas others have excluded the width of shoulder preparation and crown margin as a significant factor.

Tjan and Whang in their study evaluated four groups teeth with varying thicknesses: $1 \mathrm{~mm}, 1 \mathrm{~mm}$ with a $60^{\circ}$ bevel, $2 \mathrm{~mm}$, and $3 \mathrm{~mm}$ of remaining buccal dentin. No significant differences were noted between the different groups. While the two groups of 1 $\mathrm{mm}$-thick dentin can have more failure rate due to fracture than cement failure. ${ }^{13}$ Similarly, Sorensen and Engelman in 1990 seemed to negate the importance of dentin thickness. However, their study looked at the thickness of dentin at the margin when using various contrabevel ferrule designs, rather than at the thickness of the coronal extension of dentin. ${ }^{6}$

It is the thickness of the coronal extension above the crown margin that is significant in the fracture resistance of crowned teeth.

\section{Number of Walls and Ferrule Location}

Al-Wahadni and Gutteridge in 2002 evaluated the effect of a partial ferule on anterior teeth. They compared anterior teeth with no ferrule with teeth with $3 \mathrm{~mm}$ or more height of ferrule on the buccal surface alone. They concluded that teeth with retained buccal dentin of $3 \mathrm{~mm}$ height with no other dentin walls remaining had significantly higher resistance to fracture compared with the control. ${ }^{14}$ Based on the literatures, it is suggested that a nonuniform ferrule is superior to no ferrule at all.

Another study by $\mathrm{Ng}$ et al. investigated the common clinical scenario of only a partial ferrule being present due to destruction by the caries process. They suggested that to resist occlusal forces, it is the presence of sound tooth structure that is more important than having $360^{\circ}$ of circumferential axial wall dentin. ${ }^{15}$

\section{Factors Affecting Ferrule Design}

\section{Type of Tooth and the Extent of Lateral Load}

Two factors that distinguish anterior from posterior teeth are the relative size and the direction of loads they need to withstand. An analysis of force distribution in different teeth shows that anterior teeth are loaded laterally and posterior teeth in normal function have the majority of the load in an occlusogingival direction. Lateral forces have a greater potential to damage the tooth-restoration interface when compared with vertical loads. ${ }^{16}$

Literature reviews done by Torbjorner and Fransson concluded that a favorable occlusal prosthesis design is important for survival of structurally compromised endodontic-treated teeth than is the type of post used, as nondesirable forces introduced by way of an interference on the restoration are a risk of fatigue fracture of teeth. ${ }^{17,18}$

Hence, different analyses and treatment modalities need to be adopted when it comes to the restoration of anterior and posterior teeth. The factors concerning anterior teeth are deep bite situations, parafunction, and dietary habits, whereas in posterior teeth, it is the occlusal scheme patterns and cuspal heights that significantly influence the type and direction of load. ${ }^{19,20}$ For this reason, conclusions drawn from the literature relating to the restoration of anterior teeth should not automatically be assumed for the posterior teeth and vice versa.
It is recommended that before restoring a tooth, a thorough review of the occlusal pattern as well as functional and parafunctional forces is performed, as these will influence the success of the final restoration of the particular tooth. ${ }^{21}$

\section{Type of Post}

The dental literature relating to the different types of posts presents too many variables to enable a true comparison between all available post types. There is lacking of long-term clinical results with a high level of evidence pertaining to survival data for various post systems. ${ }^{22}$ Many studies demonstrate that the presence of a ferrule of $1.5-2 \mathrm{~mm}$ sound coronal tooth structure between the core and the finish line is more important in fracture resistance than the post design or type. Alternatively, there are many new studies favoring the reinforcement abilities of FRC posts.

A study by Saupe et al. in 1996 reported no difference in fracture resistance of teeth with bonded posts with or without a ferrule. ${ }^{23}$

\section{Core Materials}

The core material may be a further influencing factor on the effect the differing thickness of remaining dentin has on the functionality of the ferrule. A composite resin has frequently been implicated as a core material that can strengthen the tooth and reinforce cusps. ${ }^{24-28}$ Multiple studies have shown improved fracture resistance in teeth with mesioocclusodistal (MOD) cavity preparations restored with composite resin or fiber-reinforced resin. ${ }^{29-34}$ It can be assumed that dentin-bonding agents coupled with composite materials may reinforce residual tooth structure of prepared teeth and may be beneficial when only thin dentin ferrule remains.

\section{Conclusion}

The aspects considered to be the most important were the height of the ferrule, its width, the number of walls remaining and their location, and the degree of lateral load placed on the tooth. The amount of ferrule tooth structure that an abutment contains determines how resistant is a crown or bridge to the form of biomechanical failure where the fixed prosthesis separates from the abutment due to the tooth, core, and post complex on which the abutment is cemented fracturing from the abutment, such that the tooth, core, and post complex remain inside the crown or bridge when the crown or bridge separates from the abutment, with the cement that binds the crown or bridge to the tooth, core, and post complex remaining intact.

Based on the results from the various in vitro and in vivo studies, the presence of ferrule has a positive effect on fracture resistance of endodontically treated teeth. More successful prognosis could be expected if healthy dentin extending $1.5-2 \mathrm{~mm}$ coronal to the margin of the crown is provided circumferentially. If the clinical situation does not permit a $360^{\circ}$ circumferential ferrule because of extensive caries lesions, previous restorations, or fractures, an incomplete ferrule is still considered to a better option than a complete absence of ferrule.

\section{References}

1. Cheung W. A review of the management of endodontically treated teeth post, core and the final restoration. J Am Dent Assoc 2005;136(5):611-619. DOI: 10.14219/jada.archive.2005.0232.

2. Schwartz RS, Robbins JW. Post placement and restoration of endodontically treated teeth: a literature review. J Endod 2004;30(5):289-301. DOI: 10.1097/00004770-200405000-00001. 
3. Dietschi D, Duc O, Krejci I, et al. Biomechanical considerations for the restoration of endodontically treated teeth: a systematic review of the literature-part 1. Composition and micro- and macrostructure alterations. Quintessence Int 2007;38(9):733-743.

4. Cheung GS. Endodontic failures - changing the approach. Int Dent J 1996;46(3):131-138.

5. Stankiewicz NR, Wilson PR. The ferrule effect: a literature review. Int Endod J 2002;35(7):575-581. DOI: 10.1046/j.1365-2591.2002. 00557.x.

6. Sorensen JA, Engelman MJ. Ferrule design and fracture resistance of endodontically treated teeth. J Prosthet Dent 1990;63:529-536. DOI: 10.1016/0022-3913(90)90070-s.

7. Assif D, Bitenski A, Pilo R, et al. Effect of post design on resistance to fracture of endodontically treated teeth with complete crowns. J Prosthet Dent 1993;69(1):36-40. DOI: 10.1016/0022-3913(93)90237-i.

8. Mamoun JS. On the ferrule effect and the biomechanical stability of teeth restored with cores, posts, and crowns. Eur J Dent 2014;;8(2):281-286. DOI: 10.4103/1305-7456.130639.

9. Isidor F, Brøndum K, Ravnholt $\mathrm{G}$, et al. The influence of post length and crown ferrule length on the resistance to cyclic loading of bovine teeth with prefabricated titanium posts. Int J Prosthodont 1999;12(1):78-82.

10. Libman WJ, Nicholls Jl. Load fatigue of teeth restored with cast posts and cores and complete crowns. Int J Prosthodont 1995;8(2):155-161.

11. Loney RW, Kotowicz WE, McDowell GC. Three-dimensional photoelastic stress analysisof the ferrule effect in cast post and cores. J Prosthet Dent 1990;63(5):506-512. DOI: 10.1016/00223913(90)90066-L.

12. Franco ÉB, Lins do Valle $A$, Pompéia Fraga de Almeida AL, et al. Fracture resistance of endodontically treated teeth restored with glass fiber posts of different lengths. J Prosthet Dent 2014;111(1): 30-34. DOI: 10.1016/j.prosdent.2013.09.013.

13. Tjan AH, Whang SB. Resistance to root fracture of dowel channels with various thicknesses of buccal dentin walls. J Prosthet Dent 1985;53(4):496-500. DOI: 10.1016/0022-3913(85)90633-x.

14. Al-Wahadni A, Gutteridge DL. An in vitro investigation into the effects of retained coronal dentine on the strength of a tooth restored with a cemented post and partial core restoration. Int Endod J 2002;35(11):913-918. DOI: 10.1046/j.1365-2591.2002.00596.x.

15. $\mathrm{Ng} \mathrm{CCH}$, Dumbrigue HB, Al-Bayat Ml, et al. Influence of remaining coronal tooth structure location on the fracture resistance of restored endodontically treated anterior teeth. J Prosthet Dent 2006;95(4):290-296. DOI: 10.1016/j.prosdent.2006.02.026.

16. Arunpraditkul S, Saengsanon S, Pakviwat W, et al. Fracture resistance of endodontically treated teeth: three walls versus four walls of remaining coronal tooth structure. J Prosthodont 2009;18(1):49-53. DOI: 10.1111/j.1532-849X.2008.00375.x.

17. Torbjorner A, Fransson B. Biomechanical aspects of prosthetic treatment of structurally compromised teeth. Int J Prosthodont 2004;17(4):135-141. DOI: 10.1016/j.prosdent.2004.06.017.

18. Torbjorner A, Fransson B. A literature review on the prosthetic treatment of structurally compromised teeth. Int J Prosthodont 2004;17(3):369-376.
19. Okeson JP. Management of temporomandibular disorders and occlusion. St. Louis: Mosby, Inc; 2003.

20. Neff PA. Temporomandibular joint, occlusion and function. Washington DC: Georgetown University School of Dentistry; 1987.

21. Fernandes AS, Dessai GS. Factors affecting the fracture resistance of post-core reconstructed teeth: a review. Int J Prosthodont 2001;14(4):355-363.

22. Milot $P$, Stein RS. Root fracture in endodontically treated teeth related to post selection and crown design. J Prosthet Dent 1992;68(3): 428-435. DOI: 10.1016/0022-3913(92)90405-y.

23. Saupe WA, Gluskin AH, Radke RAJr, et al. A comparative study of fracture resistance between morphologic dowel and cores and a resin-reinforced dowel system in the intraradicular restoration of structurally compromised roots. Quintessence Int 1996;27(7): 483-491.

24. Reeh ES, Douglas WH, Messer HH, et al. Stiffness of endodonticallytreated teeth related to restoration technique. J Dent Res 1989;68(11):1540-1544. DOI: 10.1177/00220345890680111401.

25. Jagadish S, Yogesh BG. Fracture resistance of teeth with class 2 silver amalgam, posterior composite, and glass cermet restorations. Oper Dent 1990;15(2):42-47.

26. Hurmuzlu F, Kiremitci A, Serper A, et al. Fracture resistance of endodontically treated premolars restored with ormocer and packable composite. J Endod 2003;29(12):838-840. DOI: 10.1097/00004770-200312000-00014.

27. Ausiello P, De Gee AJ, Rengo S, et al. Fracture resistance of endodontically-treated premolars adhesively restored. Am J Dent 1997;10(5):237-241.

28. Boyer DB, Roth L. Fracture resistance of teeth with bonded amalgams. Am J Dent 1994;7(2):91-94.

29. Eakle WS. Increased fracture resistance of teeth: comparison of five bonded composite resin systems. Quintessence Int 1986;17(1): 17-20.

30. Gelb MN, Barouch E, Simonsen RJ, et al. Resistance to cusp fracture in class II prepared and restored premolars. J Prosthet Dent 1986;55(2):184-185. DOI: 10.1016/0022-3913(86)90338-0.

31. McCullock AJ, Smith BG. In vitro studies of cusp reinforcement with adhesive restorative material. Br Dent J 1986;161(12):450-452. DOI: 10.1038/sj.bdj.4806005.

32. Soares PV, Santos-Filho PCF, Martins LRM, et al. Influence of restorative technique on the biomechanical behaviour of endodontically treated maxillary premolars. Part I: fracture resistance and fracture mode. J Prosthet Dent 2008;99(1):30-37. DOI: 10.1016/S0022-3913(08) 60006-2.

33. Soares PV, Santos-Filho PCF, Gomide HA, et al. Influence of restorative technique on the biomechanical behaviour of endodontically treated maxillary premolars. Part II: strain measurement and stress distribution. J Prosthet Dent 2008;99(2):114-122. DOI: 10.1016/S00223913(08)60027-X.

34. Mondelli RFL, Ishikiriama SK, Oliveira Filho O, et al. Fracture resistance of weakened teeth restored with condensable resin with and without cusp coverage. J Appl Oral Sci 2009;17(3):161-165. DOI: 10.1590/s167877572009000300006 . 